\title{
Fe Protein-Independent Substrate Reduction by Nitrogenase MoFe Protein Variants
}

\author{
Karamatullah Danyal, ${ }^{\dagger}$ Andrew J. Rasmussen, ${ }^{\dagger}$ Stephen M. Keable, ${ }^{\|}$Boyd S. Inglet, $^{\dagger}$ Sudipta Shaw, ${ }^{\dagger}$
} Oleg A. Zadvornyy," Simon Duval, ${ }^{\dagger}$ Dennis R. Dean, ${ }^{\ddagger}$ Simone Raugei, ${ }^{\S}$ John W. Peters, ${ }^{*}, \|$ and Lance C. Seefeldt* ${ }^{\dagger}$

${ }^{\dagger}$ Department of Chemistry and Biochemistry, Utah State University, Logan, Utah 84322, United States

${ }^{\ddagger}$ Department of Biochemistry, Virginia Tech University, Blacksburg, Virginia 24061, United States

${ }^{\S}$ Center for Molecular Electrocatalysis, Pacific Northwest National Laboratory, P.O. Box 999, K2-57, Richland, Washington 99352, United States

"Department of Chemistry and Biochemistry, Montana State University, Bozeman, Montana 59717, United States

\section{Supporting Information}

ABSTRACT: The reduction of substrates catalyzed by nitrogenase normally requires nucleotide-dependent Fe protein delivery of electrons to the MoFe protein, which contains the active site FeMo cofactor. Here, it is reported that independent substitution of three amino acids $(\beta$ $98^{\mathrm{Tyr} \rightarrow \mathrm{His}}, \alpha-64^{\mathrm{Tyr} \rightarrow \mathrm{His}}$, and $\left.\beta-99^{\mathrm{Phe} \rightarrow \mathrm{His}}\right)$ located between the $\mathrm{P}$ cluster and FeMo cofactor within the MoFe protein endows it with the ability to reduce protons to $\mathrm{H}_{2}$, azide to ammonia, and hydrazine to ammonia without the need for Fe protein or ATP. Instead, electrons can be provided by the low-potential reductant polyaminocarboxylate-ligated $\mathrm{Eu}(\mathrm{II})$ ( $E_{\mathrm{m}}$ values of -1.1 to $-0.84 \mathrm{~V}$ vs the normal hydrogen electrode).

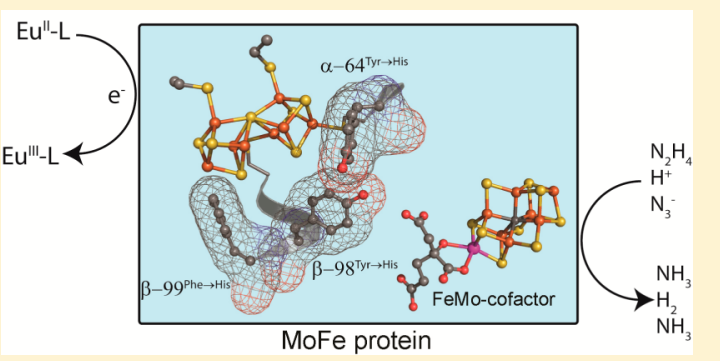
The crystal structure of the $\beta-98^{\text {Tyr } \rightarrow \text { His }}$ variant MoFe protein was determined, revealing only small changes near the amino acid substitution that affect the solvent structure and the immediate vicinity between the P cluster and the FeMo cofactor, with no global conformational changes observed. Computational normal-mode analysis of the nitrogenase complex reveals coupling in the motions of the $\mathrm{Fe}$ protein and the region of the MoFe protein with these three amino acids, which suggests a possible mechanism for how Fe protein might communicate subtle changes deep within the MoFe protein that profoundly affect intramolecular electron transfer and substrate reduction.

$\mathrm{M}$ o-dependent nitrogenase catalyzes the fixation of biological dinitrogen $\left(\mathrm{N}_{2}\right)$ to ammonia $\left(\mathrm{NH}_{3}\right)$ with the minimum reaction stoichiometry shown in eq $1:^{1,2}$

$$
\begin{aligned}
\mathrm{N}_{2} & +8 \mathrm{e}^{-}+16 \mathrm{MgATP}+8 \mathrm{H}^{+} \\
& \rightarrow 2 \mathrm{NH}_{3}+\mathrm{H}_{2}+16 \mathrm{MgADP}+16 \mathrm{P}_{\mathrm{i}}
\end{aligned}
$$

Nitrogenase consists of two component proteins called the iron $(\mathrm{Fe})$ protein and the molybdenum-iron $(\mathrm{MoFe})$ protein (Figure 1). ${ }^{1}$ The $\mathrm{MoFe}$ protein is an $\alpha_{2} \beta_{2}$ heterotetramer consisting of two catalytic $\alpha \beta$ units, each containing a $\mathrm{P}$ cluster $[8 \mathrm{Fe}-7 \mathrm{~S}]$ and a FeMo cofactor (FeMo-co; [7Fe-9S-1Mo-Chomocitrate]). ${ }^{3,4}$ The Fe protein is a homodimer with a $[4 \mathrm{Fe}-$ $4 \mathrm{~S}$ ] cluster bridging the two subunits and an ATP binding site on each subunit. ${ }^{5}$ To achieve the complete reduction of $\mathrm{N}_{2}$ at FeMo-co in the MoFe protein, a Fe protein must transiently bind to the MoFe protein. ${ }^{6}$ During this association of the two proteins, a single electron is passed from the $\mathrm{Fe}$ protein to FeMo-co, followed by the hydrolysis of the two ATP molecules bound to the $\mathrm{Fe}$ protein. ${ }^{7}$ Recent evidence suggests that the electron transfer reaction proceeds in two steps with the first step being transfer of an electron from the P cluster to FeMo- co, followed by transfer of an electron from the Fe protein to the oxidized P cluster (termed a "deficit spending" electron transfer mechanism). ${ }^{8}$ ATP hydrolysis follows the electron transfer events, with release of the $P_{i}$ and finally dissociation of the $\mathrm{Fe}$ protein from the $\mathrm{MoFe}$ protein. ${ }^{7,9}$ The two ADP molecules bound to the released Fe protein are exchanged with ATP, and the oxidized Fe protein is reduced by dithionite (in vitro) or flavodoxin/ferredoxin (in vivo). ${ }^{1,10}$ This catalytic cycle is repeated eight times to achieve the accumulation of sufficient electrons for the activation and reduction of $\mathrm{N}_{2}$ and the stoichiometric release of $\mathrm{H}_{2}{ }^{1,2}$

$\mathrm{Fe}$ protein is the only reductant known to support $\mathrm{N}_{2}$ reduction by the MoFe protein, suggesting it plays a pivotal role in the mechanism beyond simply donating electrons. Two recent reports have revealed that it is possible to deliver electrons directly to the MoFe protein in the absence of the Fe protein with reduction of a few substrates other than $\mathrm{N}_{2}$. In one case, a $\mathrm{Ru}$-ligand complex was covalently attached to the

Received: February 10, 2015

Revised: $\quad$ March 27, 2015

Published: April 1, 2015 
(A)

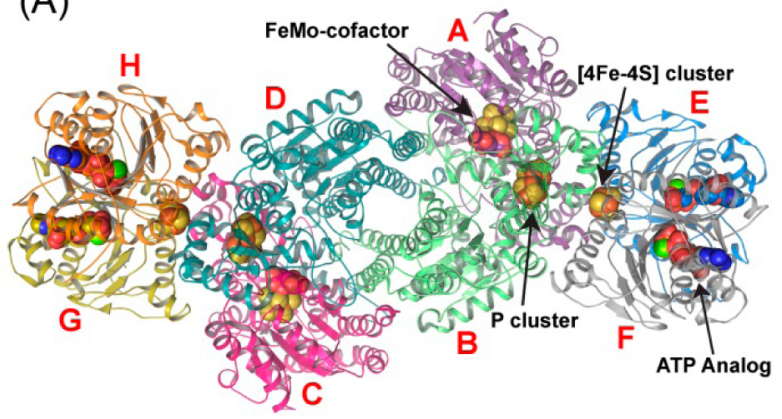

(B)

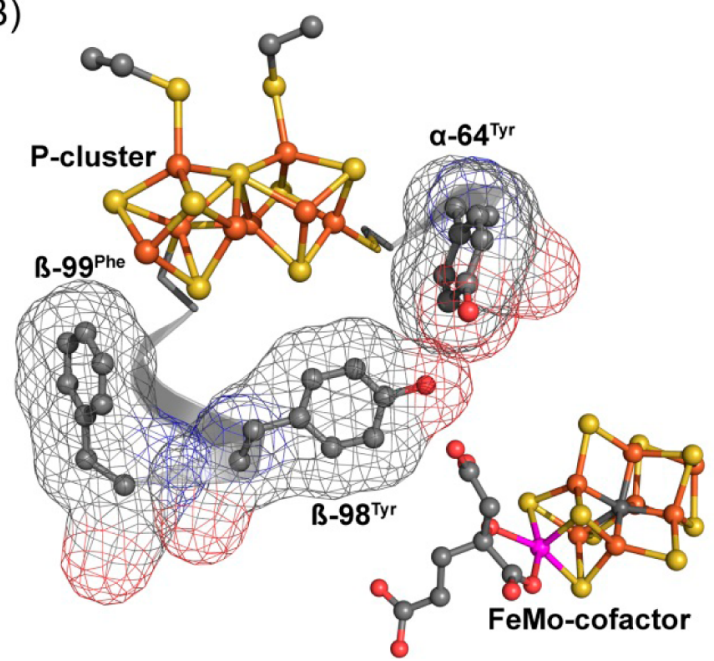

Figure 1. Nitrogenase and metal clusters. (A) Structure of the nitrogenase complex (PDB entry 2AFK). Each unit is labeled from A to $\mathrm{H}$ according to the PDB numbering. (B) Three amino acid residues relevant to the $\mathrm{Fe}$ protein-independent reduction of the substrates $\left(\mathrm{N}_{2} \mathrm{H}_{4}, \mathrm{~N}_{3}{ }^{-}\right.$, and $\left.\mathrm{H}^{+}\right)$by the MoFe protein shown in ball and stick representation with the mesh representing the van der Waals surface. Also shown are the $\mathrm{P}$ cluster and FeMo-co in ball and stick representation. The linkage from $\alpha-64^{\mathrm{Tyr}}$ to the $\mathrm{P}$ cluster ligand $\alpha$ $62^{\mathrm{Cys}}$ and from $\beta-98^{\mathrm{Tyr}}$ to the $\mathrm{P}$ cluster ligand $\beta-95^{\mathrm{Cys}}$ are also shown. Atom colors are rust for $\mathrm{Fe}$, yellow for $\mathrm{S}$, gray for $\mathrm{C}$, red for $\mathrm{O}$, and magenta for Mo.

MoFe protein, and it was possible to photoinduce transfer of an electron into the MoFe protein to achieve very low rates of reduction of the nonphysiological substrate acetylene to ethylene and cyanide to methane. ${ }^{11,12}$ In another case, substitution of a single amino acid within the MoFe protein located between the $\mathrm{P}$ cluster and FeMo-co $\left(\beta-98^{\mathrm{Tyr} \rightarrow \mathrm{His}}\right)$ allowed a $\mathrm{Eu}$-ligand complex in solution to deliver electrons to the $\mathrm{MoFe}$ protein to achieve reduction of hydrazine to ammonia at rates near those observed when electrons are delivered from the Fe protein. ${ }^{13}$ This finding suggested that amino acids located between the P cluster and FeMo cofactor within the MoFe protein might play an important but poorly understood role in regulating electron transfer events that support substrate reduction at FeMo-co.

Here, we report that independent substitution of three amino acids co-located between the $\mathrm{P}$ cluster and FeMo-co $(\beta$ $98^{\text {Tyr } \rightarrow \text { His }}, \alpha-64^{\text {Tyr } \rightarrow \text { His }}$, and $\left.\beta-99^{\text {Phe } \rightarrow \text { His }}\right)$ endows the resultant $\mathrm{MoFe}$ proteins with the ability to reduce the substrates hydrazine, azide, and $\mathrm{H}^{+}$at significant rates using $\mathrm{Eu}$ (II) ligands as a reductant without the need for the Fe protein. The crystal structure of the $\beta-98^{\mathrm{Tyr} \rightarrow \mathrm{His}} \mathrm{MoFe}$ protein was determined, revealing subtle conformational changes and altered solvent structure in the proximity of FeMo-co. These small changes between the $\mathrm{P}$ cluster and FeMo-co may mimic conformational changes requisite for catalysis. Calculations conducted on the $\mathrm{Fe}$ protein-MoFe protein complex reveal a mechanical coupling between the $\mathrm{Fe}$ protein and the region containing the $\beta-98^{\mathrm{Tyr}}, \alpha-64^{\mathrm{Tyr}}$, and $\beta-99^{\mathrm{Phe}}$ amino acids within the MoFe protein, providing a possible mechanism for the communication between the $\mathrm{Fe}$ protein and key determinants of $\mathrm{MoFe}$ protein intramolecular electron transfer.

\section{EXPERIMENTAL PROCEDURES}

Materials, Protein Purification, and Activity Assays. All reagents, unless stated otherwise, were purchased from SigmaAldrich Chemicals (St. Louis, MO). MoFe proteins were expressed in Azotobacter vinelandii strains DJ939 ( $\left.\beta-98^{\mathrm{Tyr} \rightarrow \mathrm{His}}\right)$, DJ1956 $\left(\beta-99^{\text {Phe } \rightarrow \text { His }}\right)$, and DJ1957 $\left(\alpha-64^{\text {Tyr } \rightarrow \text { His }}\right)$ that were grown as described previously. ${ }^{14}$ The MoFe proteins from each strain were purified, with some modifications, as described to $>95 \%$ purity and confirmed by sodium dodecyl sulfatepolyacrylamide gel electrophoresis analysis using Coomassie blue staining. ${ }^{14}$ Manipulation of proteins was done in septumsealed serum vials under an argon atmosphere. All transfers of gases and liquids were conducted using gastight syringes. Azide reduction, $\mathrm{H}_{2}$ evolution, and $\mathrm{N}_{2} \mathrm{H}_{4}$ reduction activities were determined as described previously. ${ }^{15} \mathrm{NH}_{3}$ was quantified using a fluorescence method with $o$-phthalaldehyde as described previously. ${ }^{15}$ For all assays, Eu(II)-L was generated by electrochemical reduction, as described previously. ${ }^{16}$

Crystallization. Crystallization trials were performed on $\beta$ $98^{\mathrm{Tyr} \rightarrow \text { His }} \mathrm{MoFe}$ protein that was concentrated to $\sim 30 \mathrm{mg} / \mathrm{mL}$ and stored in the purification buffer. All trials were conducted under anaerobic conditions in a nitrogen atmosphere glovebox (UniLAB, M. Braun) using a microcapillary batch diffusion method. ${ }^{17,18}$ Crystallization was accomplished as previously described using a precipitating solution that contained 30\% polyethylene glycol (PEG) 4000, $100 \mathrm{mM}$ Tris-HCl (pH 8.0), $190 \mathrm{mM}$ sodium molybdate, and $1 \mathrm{mM}$ sodium dithionite. ${ }^{19}$ Crystals of a dark brown color with the approximate dimensions of $100 \mu \mathrm{m} \times 200 \mu \mathrm{m} \times 200 \mu \mathrm{m}$ were observed after they had grown for 4-6 weeks. The crystals were cryoprotected by diffusion of mother liquor doped with $\sim 15 \%$ glycerol. Crystals were harvested under a stream of continuous argon on rayon loops and immediately flash-cooled in liquid nitrogen. Data were collected on beamline BL-9-2 at the Stanford Synchrotron Radiation Laboratory under a continuous flow of liquid nitrogen at $\sim 100 \mathrm{~K}$. A data set was collected at $\lambda$ $=0.97$ on a MAR 325 detector up to resolution $1.97 \AA$ and was scaled and integrated using the HKL2000 software package. ${ }^{20}$

The unit cell parameters of the collected data were nearly isomorphous to the published native structure (PDB entry 3U7Q). Initial rigid body fitting and refinement were performed using AutoMR of the CCP4 suite of programs. ${ }^{21}$ Calculation of electron density maps and model fitting were accomplished by using Coot, and the model was refined using REFMAC5 to $1.97 \AA$ resolution. ${ }^{22}$ The final model was built with a crystallographic $R$ of 21.5 , with $95.6 \%$ of the residues in the most favored Ramachandran regions and $4.2 \%$ in additionally allowed regions (Table S1 of the Supporting Information). The PDBeFold Structure Similarity server at the European Bioinformatics Institute (http://www.ebi.ac.uk/msd$\mathrm{srv} / \mathrm{ssm} /)$ was used to determine an average root-mean-square deviation (rmsd) of $0.2 \AA$ between analogous $\alpha$-carbons of the 
$\beta-98^{\mathrm{Tyr} \rightarrow \mathrm{His}} \mathrm{MoFe}$ variant and the wild-type MoFe structure (PDB entry 3U7Q).

Normal-Mode Analysis. To characterize the mechanical aspects of the long time scale dynamics of the nitrogenase complex, we performed a normal-mode analysis based on the anisotropic Gaussian network model. ${ }^{23,24}$ The nitrogenase complex was represented by beads centered at the position of the $\alpha$-carbons. According to this model, two beads are connected with a harmonic spring if they are within a cutoff distance, $R_{\text {cut }}$ and not connected otherwise. To improve the stability of the model, in this study the force constant, $k$, of the spring was chosen to vary smoothly from $k_{0}$ to zero using the sigmoidal switching function around $R_{\text {cut }}$ given in eq $2 .^{25,26}$

$$
k\left(r_{i j}\right)=\frac{k_{0}}{1+\mathrm{e}^{\left(r_{i j}-R_{\text {cut }}\right) / \gamma}}
$$

where $r_{i j}$ is the distance between beads $i$ and $j$ and $\gamma$ is the width of the switching function. We used a cutoff distance $R_{\text {cut }}$ of 12 $\AA$, with a width for the switching function of $2 \AA$. Different choices gave consistent results, in agreement with previous reports. $^{25}$

According to this model, the potential energy function of the protein is given by eq 3 :

$$
V=\frac{1}{2} \sum_{i, j=1}^{N} \sum_{\alpha, \beta=x, y, z} k\left(r_{i j}\right) \Delta r_{i}^{\alpha} \Gamma_{i j}^{\alpha \beta} \Delta r_{j}^{\beta}
$$

where $\Delta r_{i}^{\alpha}$ is the $\alpha$ component $(\alpha=x, y$, and $z$ ) of position vector $\mathbf{r}_{i}$ for the $i$ th $\alpha$-carbon and $\Gamma$ is the so-called contact matrix. The off-diagonal and diagonal elements of the contact matrix are given by eqs 4 and 5, respectively:

$$
\begin{aligned}
\Gamma_{i j}^{\alpha \beta} & =\frac{k\left(r_{i j}\right)}{k_{0}} \frac{\mathbf{r}_{i} \cdot \mathbf{e}_{\alpha}}{\left|\mathbf{r}_{i}\right|} \frac{\mathbf{r}_{j} \cdot \mathbf{e}_{\beta}}{\left|\mathbf{r}_{j}\right|} \\
\Gamma_{i i}^{\alpha \alpha} & =-\sum_{\substack{k=1 \\
k \neq i}}^{N} \sum_{\beta} \Gamma_{i k}^{\alpha \beta}-\sum_{\beta \neq \alpha} \Gamma_{i i}^{\alpha \beta}
\end{aligned}
$$

where $\mathbf{e}_{\alpha}$ is the unit vector along Cartesian direction $\alpha$. The correlations between the fluctuations of the protein residues were analyzed in terms of the covariance matrix $\mathbf{C}$, whose elements $C_{i j}=\sum_{\alpha}\left\langle\Delta r_{i}^{\alpha} \Delta r_{i}^{\alpha}\right\rangle$ were calculated from the eigenvector decomposition of the inverse of the contact matrix (eq 6): ${ }^{24}$

$$
C_{i j}=\frac{3 k_{\mathrm{B}} T}{k_{0}} \sum_{\alpha}\left[\Gamma^{-1}\right]_{i j}^{\alpha \alpha}=\frac{3 k_{\mathrm{B}} T}{k_{0}} \sum_{k=7}^{3 N} \sum_{\alpha} \lambda_{k}^{-1}\left[\mathbf{v}_{k} \cdot \mathbf{v}_{k}^{\mathbf{T}}\right]_{i j}^{\alpha \alpha}
$$

where $\lambda_{k}$ and $\mathbf{v}_{k}$ are the $k$ th eigenvalue and eigenvector of the contact matrix, respectively. The six zero-frequency modes corresponding to rigid body translations and rotations of the nitrogenase complex are excluded from the summation over the normal modes. Diagonal elements of the covariance matrix are proportional to the $\beta$ factor of the amino acid residues, $\beta_{i}=$ $8 \pi^{2} C_{i i} / 3$. As one can see in eq 6 , the spring constant $k_{0}$ acts as a mere scaling factor for the atomic fluctuations and the $\beta$ factors, and its value was chosen to reproduce the average magnitude of the crystallographic $\beta$ factors. The model is able to reproduce faithfully the relative magnitude of the experimental $\beta$ factors (Figure S1 of the Supporting Information), making us confident that it is also able to describe the overall large amplitude motions of the nitrogenase complex.

The calculations were performed on the crystal structure of the complex between the $\mathrm{Fe}$ protein and the MoFe protein from Azotobacter vinelandii with an ATP analogue and ADP bound to the $\mathrm{Fe}$ protein (PDB entries 2AFK and 2AFI, respectively). ${ }^{27}$

\section{RESULTS AND DISCUSSION}

The recent preliminary finding that substitution of $\beta-98^{\text {Tyr } \rightarrow \text { His }}$ in the MoFe protein allows it to reduce hydrazine to ammonia without participation of the Fe protein or ATP, but instead with electrons coming from Eu(II)-DTPA, points to participation of the protein around $\beta-98^{\mathrm{Tyr}}$ in the MoFe protein in regulating electron transfer between the P cluster and FeMo-co or in the reactivity of FeMo-co. ${ }^{13}$ To further explore this possibility, we have prepared $\mathrm{MoFe}$ proteins having independent amino acid substitutions for three amino acids co-localized between the $\mathrm{P}$ cluster and FeMo-co $\left(\beta-98^{\text {Tyr } \rightarrow \text { His }}, \beta-99^{\text {Phe } \rightarrow \text { His }}\right.$, and $\left.\alpha-64^{\text {Tyr } \rightarrow \text { His }}\right)$ (Figure 1). The amino acid substitutions did lower the proton reduction to $\mathrm{H}_{2}$ rate driven by the Fe protein and ATP to 1100 $\pm 25 \mathrm{nmol}$ of $\mathrm{H}_{2} \mathrm{~min}^{-1} \mathrm{mg}^{-1}$ for $\beta-98^{\text {Tyr } \rightarrow \text { His }}$ and to below detection for the $\beta-99^{\mathrm{Phe} \rightarrow \mathrm{His}}$ and $\alpha-64^{\mathrm{Tyr} \rightarrow \mathrm{His}}$ variants. The wildtype rate is $\sim 2000 \mathrm{nmol}$ of $\mathrm{H}_{2} \mathrm{~min}^{-1}$ ( $\mathrm{mg}$ of MoFe protein $)^{-1}$.

The three variant MoFe proteins were tested for their ability to reduce substrates without $\mathrm{Fe}$ protein, but instead with electrons coming from $\mathrm{Eu}$ (II) ligands. For these assays, $\mathrm{Eu}(\mathrm{II})$ and DTPA were added simultaneously to initiate the assay with no Fe protein added. Figure 2 shows the time dependence for the reduction of hydrazine $\left(\mathrm{N}_{2} \mathrm{H}_{4}\right)$ to ammonia $\left(\mathrm{NH}_{3}\right)$ for the three variant proteins with rates ranging from 167 to $708 \mathrm{nmol}$ of $\mathrm{NH}_{3} / \mathrm{mg}$ of $\mathrm{MoFe}$ protein over $25 \mathrm{~min}$. Activity was dependent on addition of Eu(II), DTPA, hydrazine, and MoFe protein. The reduction of hydrazine $\left(\mathrm{N}_{2} \mathrm{H}_{4}\right)$ is a unique

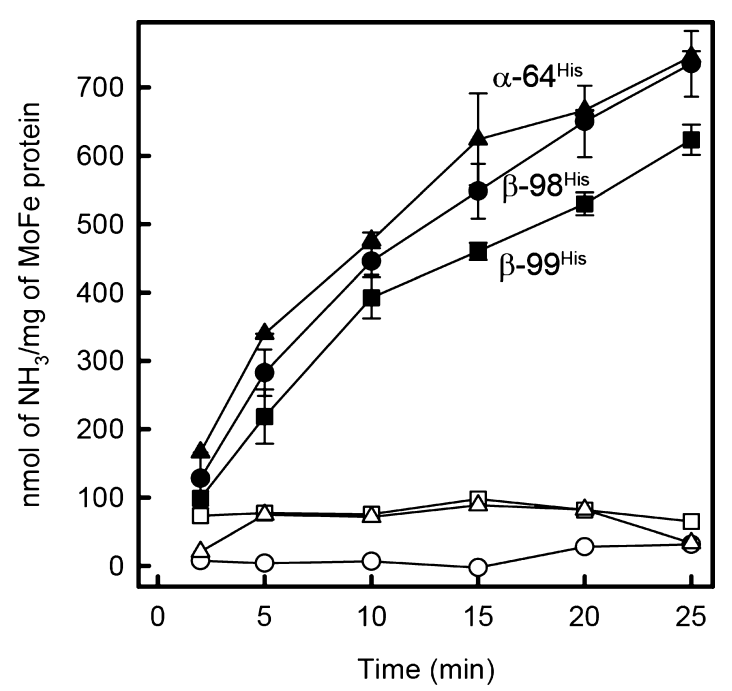

Figure 2. Fe protein-independent hydrazine reduction catalyzed by MoFe protein variants. Time course of the reduction of hydrazine to ammonia reported as nanomoles of ammonia formed per milligram of MoFe protein catalyzed by $\alpha-64^{\mathrm{His}}(\boldsymbol{\Lambda}), \beta-98^{\mathrm{His}}(\boldsymbol{O})$, or $\beta-99^{\mathrm{His}}(\boldsymbol{\square})$ variant MoFe protein. The corresponding empty symbols are the no protein controls. These assays were performed with a final concentration of $1 \mathrm{mM}$ Eu(II)-DTPA, $2.9 \mathrm{nmol}$ of $(1.83 \mu \mathrm{M})$ MoFe protein, and $100 \mathrm{mM}$ hydrazine at $25^{\circ} \mathrm{C}$. Bars represent the standard deviation for two measurements. 
property of these variant MoFe proteins compared to the wildtype MoFe protein alone, which is unable to reduce hydrazine with $\mathrm{Eu}-\mathrm{L}$ as an electron donor.

When the hydrazine reduction assay with Eu(II)-DTPA as a reductant was conducted for short times ( $2 \mathrm{~min})$, high activity could be achieved because the Eu-DTPA was stable for only short times. Under these optimal conditions, the maximal specific activity for hydrazine reduction at $100 \mathrm{mM}$ hydrazine was found to be $300 \pm 15 \mathrm{nmol}$ of $\mathrm{NH}_{3} \mathrm{~min}^{-1}$ (mg of MoFe protein $)^{-1}$ for $\alpha-64^{\mathrm{Tyr} \rightarrow \mathrm{His}}, 180 \pm 3 \mathrm{nmol}$ of $\mathrm{NH}_{3} \mathrm{~min}^{-1}$ (mg of MoFe protein $)^{-1}$ for $\beta$-98 $98^{\mathrm{Tyr} \rightarrow \text { His }}$, and $150 \pm 2 \mathrm{nmol}$ of $\mathrm{NH}_{3}$ $\min ^{-1}$ (mg of MoFe protein) $)^{-1}$ for $\beta-99^{\text {Phe } \rightarrow \text { His. These rates of }}$ hydrazine reduction compare to the rate of $320 \mathrm{nmol}$ of $\mathrm{NH}_{3}$ $\mathrm{min}^{-1}$ (mg of $\mathrm{MoFe}$ protein $)^{-1}$ catalyzed by the wild-type $\mathrm{MoFe}$ protein with $\mathrm{Fe}$ protein as the electron donor.

For the $\beta-98^{\mathrm{Tyr} \rightarrow \mathrm{His}}, \quad \beta-99^{\mathrm{Phe} \rightarrow \mathrm{His}}$, and $\alpha-64^{\mathrm{Tyr} \rightarrow \mathrm{His}} \mathrm{MoFe}$ protein variants, the rate of reduction of hydrazine was dependent on the concentration of Eu(II)-DTPA (Figure S2 of the Supporting Information), with saturation being approached above $1 \mathrm{mM} \mathrm{Eu(II)-DTPA.} \mathrm{These} \mathrm{findings} \mathrm{indicate}$ that it is possible to saturate for the reductant and that there is a finite binding affinity.

In addition, the rates of hydrazine reduction were dependent on the concentration of hydrazine (Figure 3). Fits of the data to

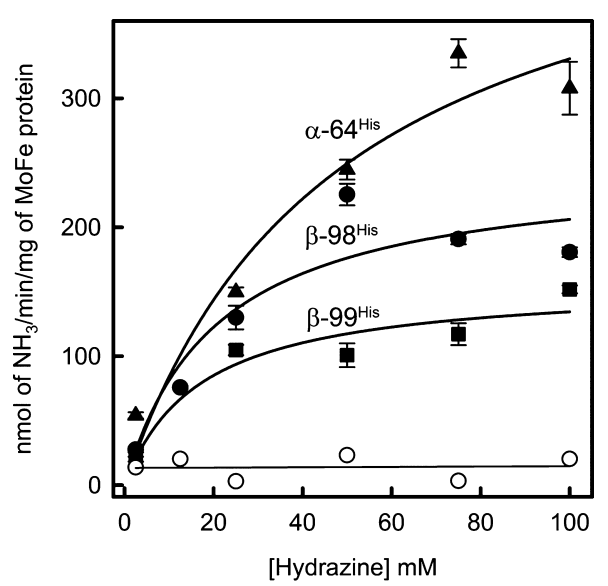

Figure 3. Concentration dependence of hydrazine on $\mathrm{MoFe}$ protein substrate reduction. The nanomoles of ammonia per $\mathrm{mg}$ of $\mathrm{MoFe}$ protein for the $\alpha-64^{\mathrm{His}}(\boldsymbol{\Delta}), \beta-98^{\mathrm{His}}(\boldsymbol{\bullet})$, and $\beta-99^{\mathrm{His}}(\boldsymbol{\square})$ variants as a function of hydrazine concentration are shown. The empty symbol corresponds to a no protein background control. All assays were conducted for $2 \mathrm{~min}$ at $25{ }^{\circ} \mathrm{C}$ with a final concentration of $1 \mathrm{mM}$ $\mathrm{Eu}$ (II) DTPA, $100 \mathrm{mM}$ hydrazine, and $2.9 \mathrm{nmol}$ of $(1.83 \mu \mathrm{M}) \mathrm{MoFe}$ protein. The data were fit to Michaelis-Menten equation (-) using SigmaPlot with $r^{2}$ values of $0.94,0.87$, and 0.91 for the $\alpha-64^{\mathrm{His}}, \beta-98^{\mathrm{His}}$, and $\beta-99^{\mathrm{His}} \mathrm{MoFe}$ protein data, respectively.

the Michaelis-Menten equation gave $K_{\mathrm{m}}$ values of $\sim 48 \mathrm{mM}$ for $\alpha-64^{\text {Tyr } \rightarrow \text { His }}, 21 \mathrm{mM}$ for $\beta-98^{\text {Tyr } \rightarrow \text { His }}$, and $17 \mathrm{mM}$ for $\beta-99^{\text {Phe } \rightarrow \text { His }}$. $V_{\max }$ values were found to be $\sim 490 \mathrm{nmol}$ of $\mathrm{NH}_{3} \mathrm{~min}^{-1}$ (mg of MoFe protein $)^{-1}$ for $\alpha-64^{\text {Tyr } \rightarrow \text { His }}, 250 \mathrm{nmol}$ of $\mathrm{NH}_{3} \mathrm{~min}^{-1}(\mathrm{mg}$ of MoFe protein $)^{-1}$ for $\beta-98^{\text {Tyr } \rightarrow \text { His }}$, and $160 \mathrm{nmol}$ of $\mathrm{NH}_{3}$ $\min ^{-1}(\mathrm{mg} \text { of } \mathrm{MoFe} \text { protein })^{-1}$ for $\beta-99^{\text {Phe } \rightarrow \text { His }}$.

The $\beta-98^{\text {Tyr } \rightarrow \text { His }}, \beta-99^{\text {Phe } \rightarrow \text { His }}$, and $\alpha-64^{\text {Tyr } \rightarrow \text { His }}$ variant MoFe proteins were found to reduce azide $\left(\mathrm{N}_{3}^{-}\right)$to ammonia (monitored) with $\mathrm{Eu}(\mathrm{II})-\mathrm{DTPA}$ as the electron donor (Table 1). The reduction midpoint potential of $\mathrm{Eu}(\mathrm{II})$ can be modified by changing the polyaminocarboxylate ligand (DTPA, EGTA, or EDTA). The Eu ${ }^{\mathrm{III} / \mathrm{II}}-\mathrm{DTPA}, \mathrm{Eu}^{\mathrm{III} / \mathrm{II}}-\mathrm{EGTA}$, and $\mathrm{Eu}^{\mathrm{III} / \mathrm{II}}$ -
Table 1. Product Formation of MoFe Protein Variants Using Eu(II)-L as a Reductant ${ }^{a}$

\begin{tabular}{|c|c|c|c|c|c|}
\hline \multirow[b]{2}{*}{ protein } & \multirow{2}{*}{$\begin{array}{c}\text { hydrazine } \\
\text { (nmol of } \\
\mathrm{NH}_{3} / \mathrm{mg} \text { of } \\
\text { MoFe } \\
\text { protein) } \\
\text { Eu-DTPA }\end{array}$} & \multicolumn{3}{|c|}{$\begin{array}{c}\text { azide (nmol of } \mathrm{NH}_{3} / \mathrm{mg} \text { of } \mathrm{MoFe} \\
\text { protein) }\end{array}$} & \multirow{2}{*}{$\begin{array}{c}\text { proton } \\
\text { (nmol of } \\
\mathrm{H}_{2} / \mathrm{mg} \text { of } \\
\mathrm{MoFe} \\
\text { protein) } \\
\text { Eu-EDTA }\end{array}$} \\
\hline & & Eu-DTPA & & Eu-EDTA & \\
\hline$\alpha-64^{\mathrm{His}}$ & $662 \pm 29$ & $108 \pm 8$ & $150 \pm 21$ & $167 \pm 29$ & $\mathrm{ND}^{b}$ \\
\hline$\beta-98^{\mathrm{His}}$ & $650 \pm 8$ & $125 \pm 4$ & $104 \pm 8$ & $79 \pm 16$ & $262 \pm 24$ \\
\hline$\beta-99^{\mathrm{His}}$ & $530 \pm 21$ & $\mathrm{ND}^{b}$ & $137 \pm 12$ & $92 \pm 8$ & $\mathrm{ND}^{b}$ \\
\hline
\end{tabular}

${ }^{a}$ Both the hydrazine and azide assays were conducted at $30{ }^{\circ} \mathrm{C}$ for 20 min, while the proton assays were conducted for $40 \mathrm{~min}$ at $30^{\circ} \mathrm{C}$. The hydrazine concentration was $100 \mathrm{mM}$ and the azide concentration 10 $\mathrm{mM}$. All assays were performed at $\mathrm{pH} 7.0{ }^{b}$ None detected.

EDTA redox couples have reduction potentials of -1.14 , -0.88 , and $-0.84 \mathrm{~V}$ versus the normal $\mathrm{H}_{2}$ electrode (NHE), respectively. ${ }^{16}$ All three ligand complexes with $\mathrm{Eu}(\mathrm{II})$ were examined with the three variant proteins for reduction of azide to ammonia (Table 1). For some of the variants, the EGTA and EDTA complexes with Eu(II) showed higher rates of azide reduction. The $\mathrm{Eu}(\mathrm{II})$-DTPA complex catalyzes proton reduction to form $\mathrm{H}_{2}$ even in the absence of enzyme, whereas the Eu(II)-EDTA complex does not. This allowed the Eu(II)EDTA complex to be examined as a source of electrons for proton reduction to form $\mathrm{H}_{2}$ for the three proteins. Only the $\beta$ $98^{\mathrm{Tyr} \rightarrow \mathrm{His}}$ protein showed significant $\mathrm{H}_{2}$ evolution rates above background.

Structural Characterization. The structure of the $\beta$ $98^{\mathrm{Tyr} \rightarrow \text { His }} \mathrm{MoFe}$ protein was determined and refined to $1.97 \AA$ resolution and compared to the structure of the wild-type MoFe protein (PDB entry 3U7Q $1.0 \AA$ A). Subtle structural differences were observed in the immediate vicinity of the amino acid substitution and in the solvent structure immediately around FeMo-co. Most notable with respect to the later is the $\sim 1.5 \AA$ difference in the position of a water molecule coordinating homocitrate resulting from the differences in the $\mathrm{H}$ binding groups of Tyr and $\mathrm{His}$ at position $\beta$-98 (Figure 4). The histidine residue in the variant refines in a slightly different orientation relative to the tyrosine in the wildtype $\mathrm{MoFe}$ protein and may be better posed for electron transfer due to the $\delta$ orbital dominance of this residue relative to the $\pi$ orbital dominance of tyrosine. The change in side chain $\mathrm{p} K_{\mathrm{a}}$ 's may also have an effect on the active site electrostatic environment and electron transfer pathway.

Calculations on Normal-Mode Conformational Changes. The findings described above reveal that it is possible to create a MoFe protein through amino acid substitutions that can reduce a number of substrates without the Fe protein and ATP. This suggests that these substitutions might regulate electron transfer from the $\mathrm{P}$ cluster to FeMo-co and/or the reactivity of FeMo-co. The nature of these conformational changes remains elusive, but the results from this work point to the possible participation of amino acids located between the P cluster and FeMo-co. To further explore the possible communication between the Fe protein and the $\mathrm{MoFe}$ protein, the vibrational normal modes that describe the large-amplitude motions of the nitrogenase complex were calculated according to a coarse-grained description of the proteins. A covariance analysis of the displacement of amino acid residues reveals a cross correlation between the motion of the two Fe proteins (Figure S3 of the Supporting Information), 


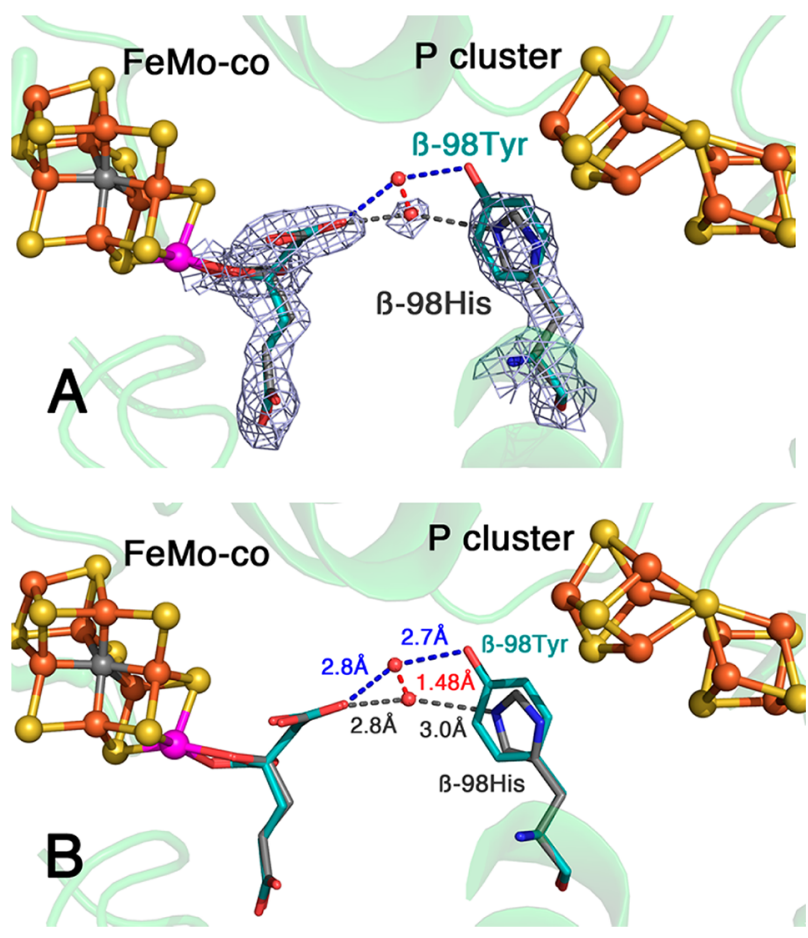

Figure 4. Crystal structure of the $\beta-98^{\mathrm{Tyr} \rightarrow \mathrm{His}}$ variant $\mathrm{MoFe}$ protein. (A) Shown is the experimental electron density superimposed with the wild-type MoFe protein (PDB entry 3U7Q). Subtle differences in structures between the two proteins are shown. (B) View of the $\beta$ $98^{\mathrm{Tyr} \rightarrow \mathrm{His}}$ variant structure superimposed with the wild-type structure (PDB entry 3U7Q), highlighting the change in the solvent structure adjacent to the FeMo cofactor.

suggesting that the motion of one of the two Fe proteins causes a response in the region between the P cluster and FeMo-co. In particular, motion of residues $\alpha-64^{\text {Tyr }}, \beta-98^{\text {Tyr }}$, and $\beta-99^{\text {Phe }}$ in the $\mathrm{MoFe}$ protein correlates with the motion of the Fe protein. Figure 5 displays the correlation between these residues and the rest of the nitrogenase complex. As one can see, there is a trivial in-phase correlation between the motion of residues $\alpha-64^{\mathrm{Tyr}}, \beta$ $98^{\mathrm{Tyr}}$, and $\beta-99^{\mathrm{Phe}}$ and the neighboring residues within the $\mathrm{MoFe}$ protein, which decays quickly in space. Remarkably, Figure 5 shows a high degree of out-of-phase correlation between these residues and the Fe proteins. The normal mode contributing most to this correlation corresponds to an out-ofphase rolling motion of the Fe proteins on the surface of the $\mathrm{MoFe}$ protein (Figure 6). These results suggest a dynamic coupling between the motion of the Fe protein and the MoFe protein region lying between the $\mathrm{P}$ cluster and FeMo-co, which may provide the key to understand the unique role of the $\mathrm{Fe}$ protein in regulating activity within the MoFe protein necessary for electron transfer and substrate reduction. The predicted motions within the MoFe protein are especially interesting because of the lack of any observed changes in different X-ray structures determined to date. ${ }^{27}$

\section{CONCLUSIONS}

Nitrogenase is a dynamic protein, with protein conformational changes playing key roles at various steps in the catalytic cycle. ${ }^{27-30}$ The absolute need for the Fe protein and ATP binding to the MoFe protein to support $\mathrm{N}_{2}$ reduction suggests that the protein-protein association communicates conformational changes within the MoFe protein essential to some aspects of catalysis, perhaps intramolecular electron transfer

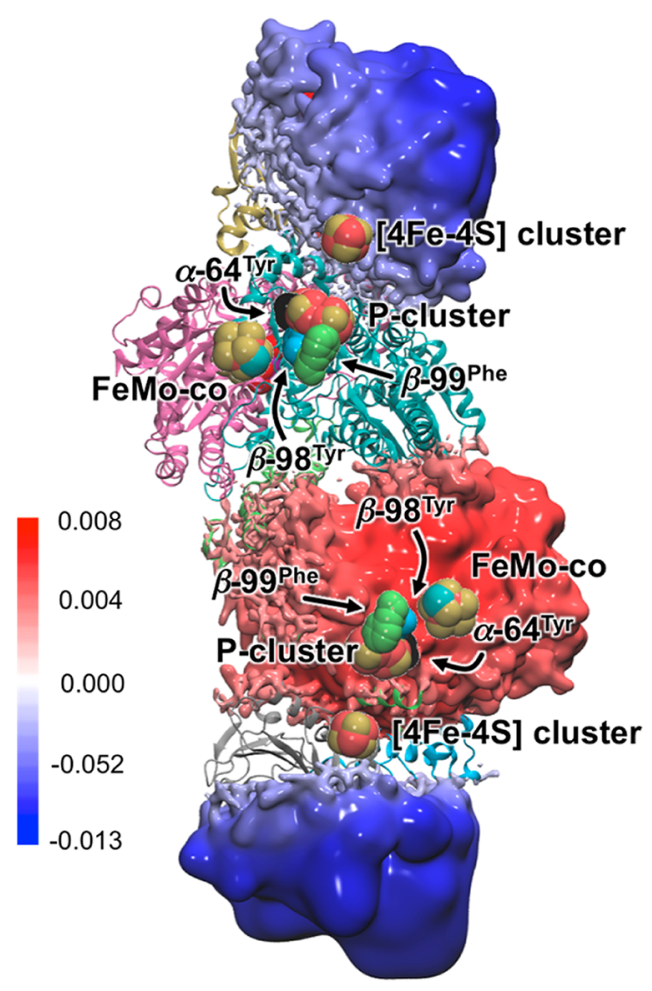

Figure 5. Mechanical coupling among residues $\alpha-64^{\mathrm{Tyr}}, \beta-98^{\mathrm{Tyr}}$, and $\beta$ $99^{\text {Phe }}$ of one of the two $\alpha \beta$ units and the rest of the MoFe protein-Fe protein complex. A similar coupling is present among the three residues of the other subunit and the rest of the complex. Regions of correlation and anticorrelation are enclosed by red and blue surfaces, respectively. The extent and color scale of the surfaces correspond to the average of the values of covariance matrix elements (in square angstroms) for the three residues. The locations of the metal clusters and $\alpha-64^{\mathrm{Tyr}}, \beta-98^{\mathrm{Tyr}}$, and $\beta-99^{\mathrm{Phe}}$ residues are shown.

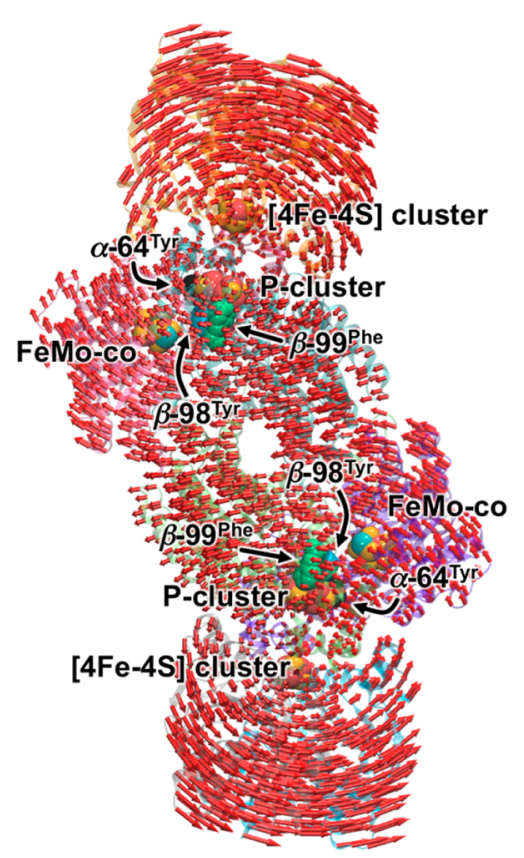

Figure 6. Collective motion corresponding to the rocking of the Fe protein on the MoFe protein surface. The length of the arrows is proportional to the displacement of the amino acid residues. The locations of the metal clusters and $\alpha-64^{\mathrm{Tyr}}, \beta-98^{\mathrm{Tyr}}$, and $\beta-99^{\text {Phe }}$ residues are shown. 
(i.e., initiation of deficit spending electron transfer) and/or substrate binding and reduction. The results presented here add to the earlier finding that substitution of amino acids buried deep within the MoFe protein located between the $\mathrm{P}$ cluster and FeMo-co can create a MoFe protein that is able to reduce a number of substrates without the Fe protein and ATP. The structure of the $\beta-98^{\mathrm{Tyr} \rightarrow \mathrm{His}}$ variant reveals no global structural differences compared to the wild-type structure, with small changes localized near the amino acid substitution and homocitrate-coordinated bound water. The structure reveals that subtle differences in structure coupled with the chemical difference in the amino acid side chains of tyrosine and histidine to alter the reactivity of the MoFe protein, suggesting that equally subtle changes might be sufficient when the $\mathrm{Fe}$ protein binds. Finally, computational normal-mode analysis reveals that the Fe protein and this region of the MoFe protein are connected in terms of molecular motion, suggesting a mechanism for how $\mathrm{Fe}$ protein might communicate into the $\mathrm{MoFe}$ protein to affect activity.

\section{ASSOCIATED CONTENT}

\section{S Supporting Information}

Eu-DPTA concentration dependence, covariance matrix for the motions within the nitrogenase complex, and a table of X-ray data statistics. This material is available free of charge via the Internet at http://pubs.acs.org.

\section{Accession Codes}

The coordinate file for the $\beta-98^{\mathrm{His}} \mathrm{MoFe}$ protein was deposited with the Protein Data Bank (4XPI).

\section{AUTHOR INFORMATION}

\section{Corresponding Authors}

*E-mail: lance.seefeldt@usu.edu. Phone: (435) 797-3964. Fax: (435) 797-3390.

*E-mail: john.peters@chemistry.montana.edu. Phone: (406) 994-7211.

\section{Funding}

This material is based upon work supported by the U.S. Department of Energy, Office of Science, Office of Basic Energy Sciences (DE-SC0010687 and DE-SC0010834 to L.C.S. and D.R.D.), the Division of Chemical Sciences, Geosciences, and Bio-Sciences (SR), and the National Science Foundation (MCB-1330807 to J.W.P. and L.C.S.). Use of the Stanford Synchrotron Radiation Lightsource, SLAC National Accelerator Laboratory, is supported by the U.S. Department of Energy, Office of Science, Office of Basic Energy Sciences, under Contract DE-AC02-76SF00515. The SSRL Structural Molecular Biology Program is supported by the DOE Office of Biological and Environmental Research and by the National Institutes of Health, National Institute of General Medical Sciences (including Grant P41GM103393).

\section{Notes}

The authors declare no competing financial interest.

\section{ABBREVIATIONS}

$\mathrm{Fe}$ protein, iron protein of nitrogenase; MoFe protein, molybdenum-iron protein of nitrogenase; FeMo-co, ironmolybdenum cofactor; Eu(II)-L, europium(II) ligand; DTPA, diethylenetriaminepentaacetic acid; EGTA, ethylene glycol bis(2-aminoethyl ether)- $N, N, N^{\prime}, N^{\prime}$-tetraacetic acid; EDTA, ethylenediaminetetraacetic acid; $M$ cluster, iron-molybdenum cofactor; F cluster, [4Fe-4S] cluster of the Fe protein; P cluster,
[8Fe-7S] cluster of the MoFe protein; ET, electron transfer; PDB, Protein Data Bank.

\section{REFERENCES}

(1) Burgess, B. K., and Lowe, D. J. (1996) Mechanism of molybdenum nitrogenase. Chem. Rev. 96, 2983-3012.

(2) Yang, Z.-Y., Danyal, K., and Seefeldt, L. C. (2011) Mechanism of Mo-dependent nitrogenase. Methods Mol. Biol. 766, 9-29.

(3) Spatzal, T., Aksoyoglu, M., Zhang, L., Andrade, S. L. A., Schleicher, E., Weber, S., Rees, D. C., and Einsle, O. (2011) Evidence for interstitial carbon in nitrogenase FeMo cofactor. Science 334, 940.

(4) Einsle, O., Tezcan, F. A., Andrade, S. L. A., Schmid, B., Yoshida, M., Howard, J. B., and Rees, D. C. (2002) Nitrogenase MoFe-protein at $1.16 \AA$ resolution: A central ligand in the FeMo-cofactor. Science 297, 1696-1700.

(5) Georgiadis, M. M., Komiya, H., Chakrabarti, P., Woo, D., Kornuc, J. J., and Rees, D. C. (1992) Crystallographic structure of the nitrogenase iron protein from Azotobacter vinelandii. Science 257, $1653-1659$

(6) Hageman, R. V., and Burris, R. H. (1978) Nitrogenase and nitrogenase reductase associate and dissociate with each catalytic cycle. Proc. Natl. Acad. Sci. U.S.A. 75, 2699-2702.

(7) Duval, S., Danyal, K., Shaw, S., Lytle, A. K., Dean, D. R., Hoffman, B. M., Antony, E., and Seefeldt, L. C. (2013) Electron transfer precedes ATP hydrolysis during nitrogenase catalysis. Proc. Natl. Acad. Sci. U.S.A. 110, 16414-16419.

(8) Danyal, K., Dean, D. R., Hoffman, B. M., and Seefeldt, L. C. (2011) Electron transfer within nitrogenase: Evidence for a deficitspending mechanism. Biochemistry 50, 9255-9263.

(9) Lowe, D. J., Ashby, G. A., Brune, M., Knights, H., Webb, M. R., and Thorneley, R. N. F. (1995) ATP hydrolysis and energy transduction by nitrogenase. In Nitrogen Fixation: Fundamentals and Applications (Tikhonovich, I. A., Provorov, N. A., Romanov, V. I., and Newton, W. E., Eds.) pp 103-108, Springer, Dordrecht, The Netherlands.

(10) Shah, V. K., Stacey, G., and Brill, W. J. (1983) Electron transport to nitrogenase. Purification and characterization of pyruvate:flavodoxin oxidoreductase. The nifJ gene product. J. Biol. Chem. 258, 1206412068.

(11) Roth, L. E., Nguyen, J. C., and Tezcan, F. A. (2010) ATP- and iron-protein-independent activation of nitrogenase catalysis by light. $J$. Am. Chem. Soc. 132, 13672-13674.

(12) Roth, L. E., and Tezcan, F. A. (2012) ATP-uncoupled, sixelectron photoreduction of hydrogen cyanide to methane by the molybdenum-iron protein. J. Am. Chem. Soc. 134, 8416-8419.

(13) Danyal, K., Inglet, B. S., Vincent, K. A., Barney, B. M., Hoffman, B. M., Armstrong, F. A., Dean, D. R., and Seefeldt, L. C. (2010) Uncoupling nitrogenase: Catalytic reduction of hydrazine to ammonia by a MoFe protein in the absence of Fe protein-ATP. J. Am. Chem. Soc. 132, 13197-13199.

(14) Christiansen, J., Goodwin, P. J., Lanzilotta, W. N., Seefeldt, L. C., and Dean, D. R. (1998) Catalytic and biophysical properties of a nitrogenase apo-MoFe protein produced by a nifb-deletion mutant of Azotobacter vinelandii. Biochemistry 37, 12611-12623.

(15) Corbin, J. L. (1984) Liquid chromatographic-fluorescence determination of ammonia from nitrogenase reactions: A 2-min assay. Appl. Environ. Microbiol. 47, 1027-1030.

(16) Vincent, K. A., Tilley, G. J., Quammie, N. C., Streeter, I., Burgess, B. K., Cheesman, M. R., and Armstrong, F. A. (2003) Instantaneous, stoichiometric generation of powerfully reducing states of protein active sites using $\mathrm{Eu}(\mathrm{II})$ and polyaminocarboxylate ligands. Chem. Commun., 2590-2591.

(17) Ng, J. D., Gavira, J. A., and García-Ruíz, J. M. (2003) Protein crystallization by capillary counterdiffusion for applied crystallographic structure determination. J. Struct. Biol. 142, 218-231.

(18) Georgiadis, M. M., Komiya, H., Chakrabarti, P., Woo, D., Kornuc, J. J., and Rees, D. C. (1992) Crystallographic structure of the nitrogenase iron protein from Azotobacter vinelandii. Science 257, $1653-1659$. 
(19) Sarma, R., Barney, B. M., Keable, S., Dean, D. R., Seefeldt, L. C., and Peters, J. W. (2010) Insights into substrate binding at FeMocofactor in nitrogenase from the structure of an $\alpha-70^{\text {Ile }} \mathrm{MoFe}$ protein variant. J. Inorg. Biochem. 104, 385-389.

(20) Otwinowski, Z., and Minor, W. (1997) Processing of X-ray diffraction data collected in oscillation mode. In Methods in Enzymology (Charles, W., and Carter, J., Eds.) pp 307-326, Academic Press, New York.

(21) Winn, M. D., Ballard, C. C., Cowtan, K. D., Dodson, E. J., Emsley, P., Evans, P. R., Keegan, R. M., Krissinel, E. B., Leslie, A. G. W., McCoy, A., McNicholas, S. J., Murshudov, G. N., Pannu, N. S., Potterton, E. A., Powell, H. R., Read, R. J., Vagin, A., and Wilson, K. S. (2011) Overview of the CCP4 suite and current developments. Acta Crystallogr. D67, 235-242.

(22) Murshudov, G. N., Vagin, A. A., and Dodson, E. J. (1997) Refinement of macromolecular structures by the maximum-likelihood method. Acta Crystallogr. D53, 240-255.

(23) Tirion, M. M. (1996) Large amplitude elastic motions in proteins from a single-parameter, atomic analysis. Phys. Rev. Lett. 77, 1905-1908.

(24) Atilgan, A. R., Durell, S. R., Jernigan, R. L., Demirel, M. C., Keskin, O., and Bahar, I. (2001) Anisotropy of fluctuation dynamics of proteins with an elastic network model. Biophys. J. 80, 505-515.

(25) Leioatts, N., Romo, T. D., and Grossfield, A. (2012) Elastic network models are robust to variations in formalism. J. Chem. Theory Comput. 8, 2424-2434.

(26) Balabin, I. A., Yang, W., and Beratan, D. N. (2009) Coarsegrained modeling of allosteric regulation in protein receptors. Proc. Natl. Acad. Sci. U.S.A. 106, 14253-14258.

(27) Tezcan, F. A., Kaiser, J. T., Mustafi, D., Walton, M. Y., Howard, J. B., and Rees, D. C. (2005) Nitrogenase complexes: Multiple docking sites for a nucleotide switch protein. Science 309, 1377-1380.

(28) Danyal, K., Mayweather, D., Dean, D. R., Seefeldt, L. C., and Hoffman, B. M. (2010) Conformational gating of electron transfer from the nitrogenase Fe protein to MoFe protein. J. Am. Chem. Soc. 132, 6894-6895.

(29) Tezcan, F. A., Kaiser, J. T., Howard, J. B., and Rees, D. C. (2015) Structural evidence for asymmetrical nucleotide interactions in nitrogenase. J. Am. Chem. Soc. 137, 146-149.

(30) Mayweather, D., Danyal, K., Dean, D. R., Seefeldt, L. C., and Hoffman, B. M. (2012) Temperature invariance of the nitrogenase electron transfer mechanism. Biochemistry 51, 8391-8398. 